\title{
The CAHSI INCLUDES Alliance: Realizing Collective Impact
}

\section{Dr. Elsa Q. Villa, University of Texas at El Paso}

Elsa Q. Villa, Ph.D., is a research assistant professor at The University of Texas at El Paso (UTEP) in the College of Education, and is Director of the Center for Education Research and Policy Studies (CERPS). Dr. Villa received her doctoral degree in curriculum and instruction from New Mexico State University; she received a Master of Science degree in Computer Science and a Master of Arts in Education from UTEP. She has led and co-led numerous grants from corporate foundations and state and federal agencies, and has numerous publications in refereed journals and edited books. Her research interests include communities of practice, gender, transformative learning, and identity.

\section{Dr. Ann C. Gates, University of Texas at El Paso}

Dr. Ann Quiroz Gates is an AT\&T Distinguished Professor and Chair of the Computer Science Department and past Associate VP of Research and Sponsored Projects at the University of Texas at El Paso. Gates directs the NSF-funded CyberShARE Center of Excellence that has a mission to advance interdisciplinary education and research. She served on the Naval Research Advisory Committee (2016-2018) and currently serves on the NSF CISE Advisory Committee on Education and Broadening Participation. Gates leads the Computing Alliance for Hispanic-Serving Institutions, one of five National INCLUDES Alliances. She received the 2015 Great Minds in STEM's Education award, the CRA's 2015 A. Nico Habermann Award, the 2010 Anita Borg Institute Social Impact Award, and the 2009 Richard A. Tapia Achievement Award for Scientific Scholarship, Civic Science, and Diversifying Computing. She was named to Hispanic Business magazine's 100 Influential Hispanics in 2006 for her work on the Affinity Research Group model.

\section{Dr. Sanga Kim, The University of Texas at El Paso}

Dr.Kim is a Postdoctoral Research Fellow with Computing Alliance of Hispanic-Serving Instittuions (CAHSI) at the University of Texas at El Paso. She earned her doctorate in Education from the University of Iowa. Her research uses sociological perspectives to study educational equity and racial diversity in higher education, focusing on the experiences and persistence of women and underrepresented students. More specifically, she studies the impact of educational practices and co-curricular learning experiences on college student outcomes in STEM fields using quantitative methods. Her current research focuses on the higher education experiences and trajectories of Latinx and first-generation college students in STEM fields. She has published and co-authored several articles published in the following journals: Educational Evaluation and Policy Analysis, Educational Policy, Journal of Student Affairs Research and Practice, and Teachers College Record.

\section{Prof. David S. Knight, University of Washington}

David S. Knight is an assistant professor at the University of Washington. His research examines educator labor markets, school finance, and cost-effectiveness analysis. He received his $\mathrm{PhD}$ in urban education policy and MA in economics from the University of Southern California and bachelor's degrees in economics and anthropology from the University of Kansas. 


\title{
The CAHSI INCLUDES Alliance: Realizing Collective Impact
}

\begin{abstract}
To address the low number of baccalaureate degrees in computing to meet the demand for computing professionals, the Computing Alliance of Hispanic-Serving Institutions (CAHSI) was selected by the National Science Foundation (NSF) in 2018 to serve as the lead partner of a national INCLUDES alliance. The Inclusion Across the Nation of Communities of Learners (INCLUDES) initiative is one of NSF's Ten Big Ideas with the goal of broadening participation in STEM fields by creating networked relationships among organizations and across sectors, using a collaborative approach with stakeholders who share a common agenda. The CAHSI Alliance is using the collective impact framework to accelerate change in broadening participation, particularly of Latinx, in computing fields. One aspect of collective impact is using a common set of data for decision-making within and across institutions. This paper will provide a short description of our data collection and analysis process, which helps populate a dashboard that compares student outcomes for each 2- and 4-year CAHSI institution with other institutions of higher education nationally.
\end{abstract}

\section{Introduction}

Maintaining a globally competitive computing workforce in the U.S. requires expanding engagement of individuals from all sectors of our society, especially Latinx, the nation's largest minority group. While the number of degrees in computing has increased over time, the gap between Latinx and White attainment remains fixed, with Latinx representing $\sim 10 \%$ of computer science degrees awarded each year [1]. As such, in 2006 a team of faculty from seven HispanicServing Institutions (HSIs) formed the Computing Alliance for Hispanic Serving Institutions (CAHSI) to create a unified voice for consolidating the strengths, resources, and concerns of HSIs and other groups to address the shortage of computing professionals, especially Latinx. Over time, the number of CAHSI institutions grew; and, in 2018, CAHSI was awarded an INCLUDES grant from the National Science Foundation to maximize its national impact using a collective impact framework. For CAHSI INCLUDES to be a successful alliance, it must contribute to reducing that gap, which is an economic and educational equity imperative [2].

The national CAHSI INCLUDES Alliance has over 60 higher education institutions, non-profit organizations, governmental entities, and industry partners in its alliance, creating a network of committed institutions and organizations from public and private sectors to broaden participation of Hispanics in computing through its collective effort. By 2030, Hispanics are expected to represent 20 percent of the U.S. population [3]. Thus, CAHSI's vision is: By 2030, Hispanics will represent 20 percent or more of those who earn credentials in computing. Credentials are defined as degrees and certifications that lead to gainful employment and advancement in the field. This vision is referred to as the "20-30" vision of the CAHSI INCLUDES National Alliance.

\section{Collective Impact}

In order to maximize its impact, the CAHSI INCLUDES Alliance uses collective impact, a model that posits a network of committed institutions can do more together than any one institution can do alone [4]. The mission of CAHSI then is to grow and sustain a networked community committed to recruiting, retaining, and accelerating the progress of Hispanics in computing. The 
efforts will result in institutions committed to advancing Latinx students in computing at 2-year and 4-year institutions of higher education.

To create new knowledge about Latinx student success, it is important to understand progress by tracking and monitoring of individual CAHSI institutions as well as the collective of institutions in order to improve as a whole. In other words, as each CAHSI institution improves, the collective improves. Thus, this paper focuses on one aspect of collective impact: common measures. We define common measures as the metrics that are collected and used by CAHSI institutions to track their own progress and make the necessary adjustments to improve; thus, advancing toward the CAHSI 20-30 vision. As such, the expectation is that CAHSI institutions will integrate needed adjustments, such as more faculty professional development to adopt or adapt evidence-based practices and/or develop future leaders who are more effective; increase student engagement to create a more inclusive environment for Latinx students; and/or partner with other entities, such as industry or governmental agencies, to understand their needs in order to create more opportunities for Latinx students, such as internships or future employment.

\section{Common Measures}

In order to actuate common measures, The CAHSI INCLUDES Alliance created a data management team (DM) to identify a specific and meaningful set of data that CAHSI institutions could monitor each year. Despite each CAHSI institution being a Hispanic-Serving Institution (HSI), each institution has unique characteristics, given their respective local context as well as their own institutional characteristics, such as being a 4-year or 2-year institution of higher education, or an institution with no doctoral programs. These institutions also range from the minimum of 25 percent Hispanic-enrolling (to qualify as an HSI) to as high as 95 percent Hispanic-enrolling.

Given this wide range of diversity within this HSI community, how could we monitor progress? How could we be impactful if we did not have a common measurement to monitor each institution independently and the collective of institutions?

\section{Identifying Common Measures}

The DM team realized that simply looking at enrollment data or graduation rates was insufficient in fully capturing and understanding progress. Enrollment and graduation rates were increasing, especially among Latinx students generally [5] because the aggregate numbers were increasing. For instance, Hispanic enrollment in degree-granting institutions of higher education increased by 134 percent between 2000 and 2016 (from 1.4 million to 3.2 million students) [6]. The number of bachelor's degrees awarded over this period increased by 202 percent [7], and within the computing field, the percent increase was less than 50 percent over the same period [8]. Given all these increases, we acknowledge that it is important to also consider the demographic changes in the U.S. population, especially the growing share of the U.S. population as Latinx [3].

We also realized that the CAHSI's 20-30 vision was developed using a parity concept, where two measures of representation are compared. We note earlier in this paper that currently the percentage of computer science degrees awarded to Latinx is about $10 \%$; yet, the projected percentage of Hispanics in the U.S. by 2030 is $20 \%$. Thus, comparing the number of computer science degrees awarded to Latinx to the number of Hispanics in the U.S. population, we see parity has not been reached. 
Thus, this parity concept addressed our dilemma of how to define a set of common measures to monitor progress toward our 20-30 vision. Our DM team defined new measures of gender and racial/ethnic parity in computing fields to track progress and measure success. As such, "we define[d] underrepresentation as a lack of parity, where parity, in this case, is defined as the extent to which the gender and racial/ethnic makeup of one field mirrors the gender and racial/ethnic makeup of other fields at the same institution" [2, p. 2]. For racial/ethnic parity, we focus on parity for Latinx students because (a) this group represents an increasing share of the U.S. population; (b) Latinx students represent an increasing share of students in postsecondary education; and (c) the rate of enrollment of Latinx students in postsecondary education has not kept pace with growth in the Latinx population in the U.S. [5,9].

\section{Data Dashboard}

In order to establish shared data management practices for measuring progress of collective efforts, a dashboard has been conceptualized to support the use of common measures and management of the sets of data, which is a key component of the collective impact framework. This dashboard serves as a "meter" for institutions to track progress in their computing disciplines, such as computer science or computer engineering, and to serve as a decision-making tool to affect institutional/ departmental cultural shifts. Two of our dashboard meters will contain the following information: (1) completion rates and (2) departmental enrollment data; each disaggregated by Latinx vs. white non-Hispanic and gender, in particular Latina.

To populate the meters, the DM team focuses on (1) student-level data, such as course taking, grades, and surveys through established data sharing agreements with institutional research offices at Alliance institutions; and (2) publicly available data from the Integrated Postsecondary Education Data System (IPEDS) on the U.S. Department of Education website.

These two meters will allow the DM team and the CAHSI INCLUDES Alliance to track trends in students' initial enrollment and progression in students' academic outcomes through undergraduate and graduate coursework, and their grades. The complementary nature of institutional and IPEDS data will further allow the DM Team to conduct rigorous analyses and provide key stakeholders with useful information that will contribute to their continuous programmatic improvement to contribute to collective impact and improvement informed through these common measures.

In terms of the ways of sharing the data analysis, CAHSI institutions will be able to access the CAHSI website through a login to be able to access the dashboard meters. The first meter on our dashboard measures race/ethnicity and gender parity within each institution with respect to completion rates. The following formula produces these parity rates:

The basic calculation of parity is based on different versions of the following formula:

$$
\text { Racial/ethnic } \text { parity }_{i}=\frac{\text { Latinx }^{C S}}{\text { All Stu. }^{C S}}-\frac{\text { Latinx }^{A O F}}{\text { All Stu. }^{A O F}}=\% \text { Latinx }^{C S}-\% \text { Latinx }^{A O F}
$$

Where Latinx ${ }^{\mathrm{CS}} / \mathrm{All}$ stu. ${ }^{\mathrm{CS}}$ refers the total number of CS bachelor's degrees awarded at a given institution in a given year divided by the total number of CS bachelor's degrees awarded. In other words, the percent of all CS bachelor's degrees awarded to Latinx students. Similarly, Latinx ${ }^{\mathrm{AOF}}$ / All stu. ${ }^{\text {AOF }}$ refers to the percent of bachelor's degrees awarded to Latinx students in all other fields, at the same institution during the same year. Negative values imply Latinx students are 
underrepresented in computing fields, compared to enrollment in other fields. The formula can be extended to examine gender parity in computing fields or intersections of race/ethnicity and gender.

\section{Conclusion}

With these common measures situated in a data dashboard, CAHSI Alliance institutions will be able to monitor its progress year-by-year and make improvements as CAHSI moves toward realizing its 20-30 vision.

\section{References}

[1] NSF, National Science Foundation. NCSES: Women, minorities, and persons with disabilities in science and engineering. [Online]. Available NSF, NSF, National Science Foundation. NCSES: Women, minorities, and persons with disabilities in science and engineering. [Online]. Available NSF, https://ncses.nsf.gov/pubs/nsf19304/. [Accessed January 28, 2020].

[2] D. S. Knight, S. Kim, and A-M. Núñez, "Assessing gender and racial/ethnic parity in computing fields: Evidence from the Integrated Postsecondary Education Data System. Paper accepted to the 2020 Annual Meeting of the American Educational Research Association, April, San Francisco, CA, 2019.

[3] J. Vespa, D. M. Armstrong, and L. Medina, L, Demographic turning points for the United States: Population projections for 2020 to 2060, 2018. [Online]. Available, U.S. Census Bureau, https://www2.census.gov/library/publications/2018/demo/P25-1144.pdf. [Accessed January 28, 2020].

[4] J. Kania, and M. Kramer, "Collective impact," Stanford Social Innovation Review: Informing and inspiring leaders of social change, 2011. [Online]. Available: Stanford Social Innovation, https://ssir.org/articles/entry/ collective_impact. [Accessed April 15, 2016].

[5] A. Nora, and G. Crisp, "Hispanics and higher education: An overview of research, theory, and practice," in Higher Education: Handbook of Theory and Research, J. Smart. doi: 10.1007/978-1-4020-9628-0, 2009, pp. 317-353.

[6] NCES, National Center for Education Statistics, "Status and trends in the education of racial and ethnic groups: Indicator 20: Undergraduate enrollment," 2019. [Online]. Available:NCES, https://nces.ed.gov/programs/raceindicators/indicator_REB.asp. [Accessed January 28, 2020].

[7] NCES, National Center for Education Statistics. (2019). "Degrees conferred by race and sex,” 2019. [Online]. Available: NCES, https://nces.ed.gov/fastfacts/display.asp?id=72. [Accessed January 28, 2020].

[8] NCES, National Center for Education Statistics. (2019). “Table 322.30. Bachelor's degrees conferred by postsecondary institutions, by racelethnicity and field of study: 2015-16 and 2016-17," 2019. [Online]. Available: NCES https://nces.ed.gov/programs/digest/d18/tables/dt18_322.30.asp. [Accessed January 28, 2020]. 
[9] A. H. Nichols. A Look at Latino Student Success: Identifying Top-and Bottom-Performing Institutions. Washington, D.C.: Education Trust, 2017. 